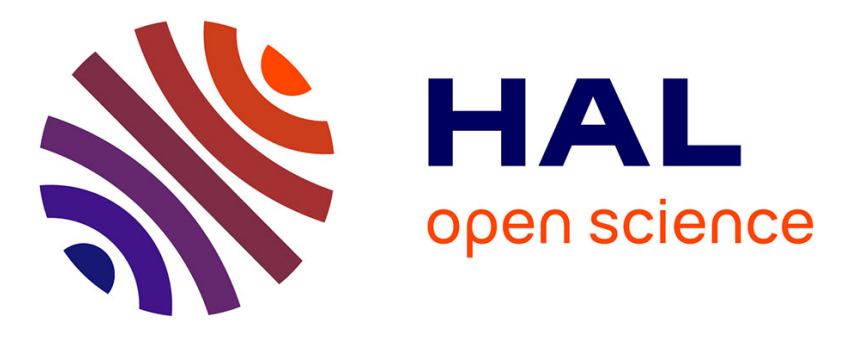

\title{
Compensation of a ball end tool trajectory in complex surface milling
}

Moez Smaoui, Zoubeir Bouaziz, Ali Zghal, Maher Baili, Gilles Dessein

\section{To cite this version:}

Moez Smaoui, Zoubeir Bouaziz, Ali Zghal, Maher Baili, Gilles Dessein. Compensation of a ball end tool trajectory in complex surface milling. International Journal of Machining and Machinability of Materials, 2012, vol. 11, pp. 51-68. 10.1504/IJMMM.2012.044923 . hal-00776716

\section{HAL Id: hal-00776716 https://hal.science/hal-00776716}

Submitted on 16 Jan 2013

HAL is a multi-disciplinary open access archive for the deposit and dissemination of scientific research documents, whether they are published or not. The documents may come from teaching and research institutions in France or abroad, or from public or private research centers.
L'archive ouverte pluridisciplinaire $\mathbf{H A L}$, est destinée au dépôt et à la diffusion de documents scientifiques de niveau recherche, publiés ou non, émanant des établissements d'enseignement et de recherche français ou étrangers, des laboratoires publics ou privés. 


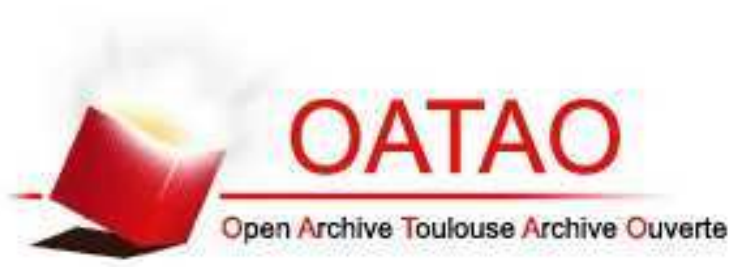

\section{Open Archive Toulouse Archive Ouverte (OATAO)}

OATAO is an open access repository that collects the work of Toulouse researchers and makes it freely available over the web where possible.

This is an author-deposited version published in: http://oatao.univ-toulouse.fr/ Eprints ID: 6548

To link to this article: DOI:10.1504/IJMMM.2012.044923

http://inderscience.metapress.com/content/g4h31123wx169484/

\section{To cite this version:}

SMAOUI, Moez and BOUAZIZ, Zoubeir and ZGHAL, Ali and BAILI, Maher and DESSEIN, Gilles Compensation of a ball end tool trajectory in complex surface milling. (2012) International Journal of Machining and Machinability of Materials, vol. $11\left(\mathrm{n}^{\circ} 1\right)$. pp. 51-68. ISSN 1748-5711

Any correspondence concerning this service should be sent to the repository administrator: staff-oatao@inp-toulouse.fr 


\title{
Compensation of a ball end tool trajectory in complex surface milling
}

\author{
M. Smaoui*, Z. Bouaziz and A. Zghal
}

Unit of Mechanics, Solids, Structures and Technological Development, Ecole supérieure des sciences et techniques, BP 56 Beb Mnara, 1008 Tunis, Tunisia

E-mail: Smaouimoez@voila.fr

E-mail: zoubeir.bouaziz@enis.rnu.tn

E-mail: ali.zghal@esstt.rnu.tn

*Corresponding author

\section{Baili and G. Dessein}

Ecole Nationale d'Ingénieurs de Tarbes, Laboratoire Génie de Production, Université de Toulouse, INP/ENIT, LGP, 47 avenue d'Azereix, BP 1629, F-65013 Tarbes Cedex, France E-mail: maher.baili@enit.fr E-mail: gilles.dessein@enit.fr

\begin{abstract}
This work is consecrated to the minimising of machining errors based on a method for the compensation of the trajectory to be machined in hemispherical milling. This compensation is found to be necessary because of the tool deflection due to the cutting forces. In order to remedy to the machining errors, caused by this deflection, a compensation method has been proposed. The latter is inspired from the mirror method, since the compensated position is going to be determined as being the trajectory reflection, deviated onto the mirror. The advantage of this proposed method is that it takes into account the three deflections $d_{x}, d_{y}$ and $d_{z}$, respectively to the directions $X, Y$ and $Z$. After that, two-parallel machinings, separated by a groove and achieved absolutely in the same conditions and with the same tool, are carried out, on the same complex part. The first machining is with compensation, but the second is without compensation.

The coordinates of the two obtained surfaces are recorded by a $3 \mathrm{D}$ measuring machine. The comparison of the two-surfaces shows the presence of an important correction of the tool trajectory, and reveals a similarity between the part obtained by simulation and the one conceived in CAM.
\end{abstract}

Keywords: milling; cutting forces; deflection; compensation.

Reference to this paper should be made as follows: Smaoui, M., Bouaziz, Z., Zghal, A., Baili, M. and Dessein, G. (2012) 'Compensation of a ball end tool trajectory in complex surface milling', Int. J. Machining and Machinability of Materials, Vol. 11, No. 1, pp.51-68. 
Biographical notes: Moez SMAOUI is an Assistant Professor of Mechanical Production at the Faculty of Sciences Gafsa in Tunisia. His research topics are CAD-CAM, cutting forces modeling and surface integrity.

Zoubeir Bouaziz is a Professor of Mechanical Production at the National Sfax Engineering School in Tunisia. His research topics are CAD-CAM, cutting forces modeling and surface integrity.

Ali Zghal is a Professor of Mechanical Engineering at Ecole supérieure des sciences et techniques in Tunisia. His research topics are numerical modelling and structure.

Maher Baili is an Assistant Professor of Mechanical Design and Production at the National Tarbes Engineering School. His research topics are machining of hard-to-cut materials, cutting forces modeling and surface integrity.

Gilles Dessein is a Full Professor of Production at the National Tarbes Engineering School. His research topics are high performance machining and CAD-CAM. His current research focus on stability and dynamics of milling process, solution against thin walled part vibrations, surface integrity and machining of hard-to-cut materials, $\mathrm{CNC}$ behaviour and process monitoring. He enlivens the research group 'Modelization and Optimization of Manufacture Processes' at the LGP and work in different European projects.

\section{Introduction}

In high-precision industrial machining environments, the machined surface quality and precision constitute important criteria at the time of machining. This precision may be altered by some machining errors. Among these errors, the one induced by the thermal effect can be mentioned. Huang and Hoshi (2000) have proposed an effective method of fixture design to reduce the machining errors caused by the cutting heat in face milling. Liu et al. (2010) afforded us with detailed processes for machining an aspheric surface which used a four-axis desktop ultraprecision and the optimisation of compensation cutting has used the Taguchi method. Concerning the tool wear Matsumura and Ono (2008) have suggested a compensation method for the wear or the deterioration of the tool cutting edge. A large portion of the dimensional errors is caused by positioning errors in the axes of motion on a machine-tool. Fines and Agah (2008) have fulfilled the application of artificial neural networks to the problem of calculating these error compensation values. In this context, Wan et al. (2008) have proposed an effective model that includes machine-tool, fixture and datum errors, within a unified framework, by means of a differential motion methodology. Furthermore, they present a compensation model of fixture errors, datum errors and the deviation of the tool coordinates.

In the framework of ball-end milling, a machining error compensation, caused by the tool deflection, is proposed. Several methods, allowing the compensation of the tool trajectory, following its deflection, are proposed in the literature. Indeed, Budak and Altintas (1994) present an approach aiming to optimise the cutting condition, with the purpose to limit, to the maximum, the machining errors, in order to correct them 
afterwards. Law and Geddam $(2001,2003)$ try to measure and control the cutting forces or the deflection errors in real-time. Their method requires important means to establish a control system, and carry out the necessary modification on the machine.

Another approach consists in compensating the tool trajectory, with the modification of this trajectory, following the prediction or the measuring of the machining errors. The latter can be estimated with a neural networks (Cho et al., 2006) or by an analytic/numerical model of the tool deflection (Cho et al., 2003; Suh et al., 1996).

In this context, a new method, tending to compensate the tool trajectory, has been proposed. This approach is inspired from the mirror method (Dépince and Hascoët, 2006; Seo, 1998), since the compensated position is going to be found out as being the reflection of the trajectory deviated onto the mirror.

Indeed, the same principle will be adopted. However, this method is going to be generalised simultaneously in the three directions $X, Y$ and $Z$, by taking into account the three flexions $d_{x}, d_{y}$ and $d_{z}$. The latter are determined according to the cutting forces $F_{X}$, $F_{Y}$ and $F_{Z}$.

In this work, the different steps to follow are going to be presented one by one, in accordance with their chronological succession, in order to end, finally, at the effective machining.

After the elaboration of the cutting forces model (Smaoui et al., 2008), all the interest is focused on the study of the tool deflection, due to these forces, with the finite elements method. This method consists in studying the tool deflection, in the three directions under the effect of the forces $F_{X}, F_{Y}$ and $F_{Z}$ applied simultaneously. It also consists in presenting the proposed compensation method. At this level, the problem consists in determining the deflected trajectory, on which the mirror method will be applied. So, the simulation of the deflected trajectory is going to be done, according to the average force between two-consecutive nodes. The whole of nodes form the CAM trajectory. The forces cited above depend on the inclination angle $\alpha$ according to the $X$ axis, measured instantaneously by the tangent.

The deflected trajectory is the vector formed by the CAM trajectory, deviated by the average forces and calculated previously. The choice of the average forces is justified by the inability to indicate, with precision, the force-intensities at the level of each CAM point. These force-intensities can be comprised only between a minimum and a maximum.

A compensation algorithm, inspired from the mirror method, is going to be adopted. It will allow to correct the tool deflected trajectory, all along the part.

The coordinates, which constitute the corrected tool trajectory, are sent afterwards to the CAM software $\left(\right.$ MasterCam $^{\odot}$ ), to control the machine.

Finally, two-parallel machinings, separated by a groove and executed absolutely in the same conditions and with the same tool, will be carried out on the same complex part, the first with compensation while the second is done without compensation.

The coordinates of the two obtained surfaces will be taken by a 3D measuring machine. The difference between these two-surfaces corresponds to the deflection average value, occurring in that area. It was ineluctably shown that the compensated surface has improved of the deflection value, which makes it considerably and effectively nearest to the surface conceived in CAM. 


\section{Calculation and simulation of the cutting tool deflection error}

\subsection{Cutting forces model}

The cutting forces model is based upon the discretisation of the tool, into a series of elementary discs, all along the axial depth. The local radius $R(z)$ of the elementary disc, or of each circumference, can be given under the following form:

$$
R(z)=\sqrt{R^{2}-(R-z)^{2}}
$$

With $R$ the tool radius and ' $z$ ' the height of each disc (Figure 1).

The elementary cutting forces can be calculated at any point $P$, the middle of each discretised section, in the two-directions. The first is an axial direction, following the $Z$ axis in $N_{z}$ increments. Each one bears the index, $i(i=1,2, \ldots, N)$, counted from the point $O$. The second is an angular discretisation in $N_{\theta}$ increments, counted from the $Y$ axis. Each increment bears the index $j\left(j=1,2, \ldots, N_{\theta}\right)$.

Figure 1 Cutting forces applied to the tool (see online version for colours)
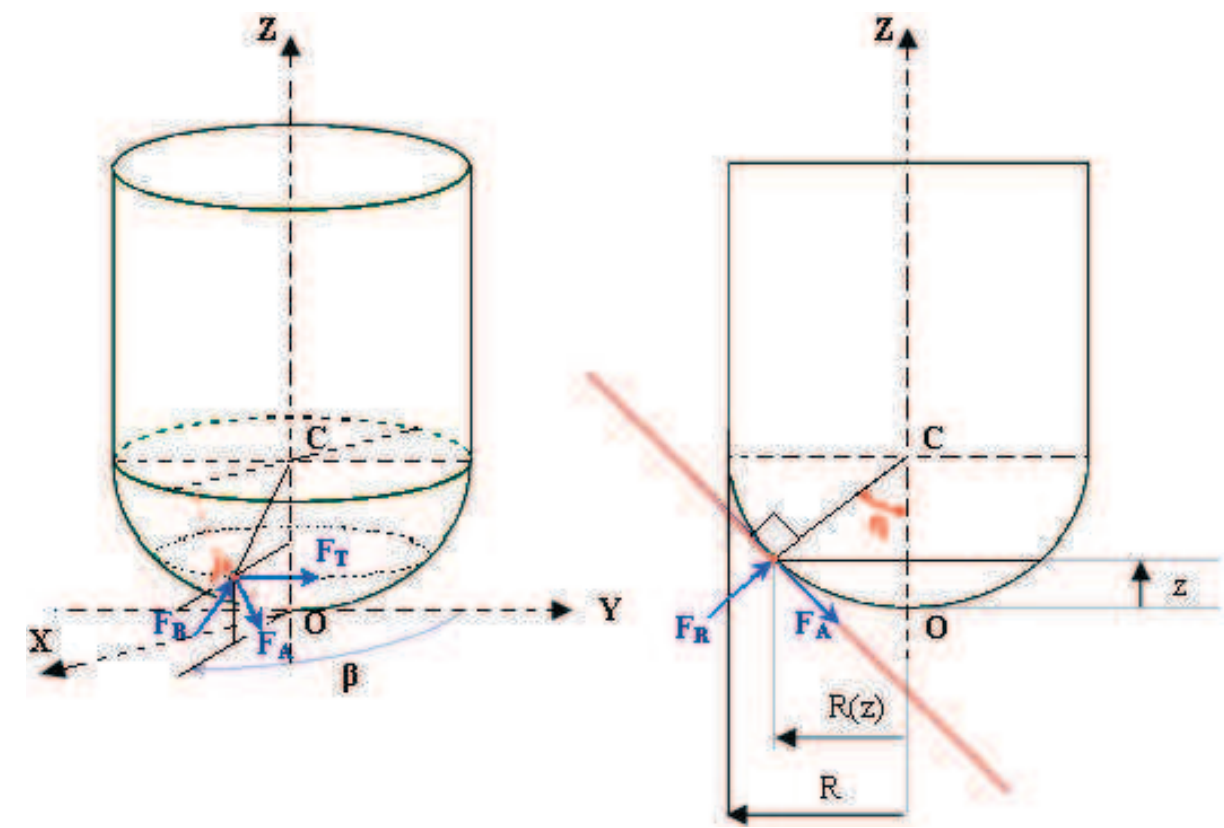

The total cutting force for the $j$ position is:

$$
\left[\begin{array}{l}
d F_{X}(j) \\
d F_{Y}(j) \\
d F_{Z}(j)
\end{array}\right]=\sum_{i=1}^{N_{z}} \sum_{k=1}^{N_{f}}[T]_{\mathfrak{R}_{c}}^{\Re_{s}}(i, j, k)\left[\begin{array}{l}
K_{R} \\
K_{T} \\
K_{A}
\end{array}\right] f_{z_{b}} \sin [\beta(i, j, k)] d z
$$

matrix of the transfer from $\mathfrak{R}_{S}(C, \vec{R}, \vec{T}, \vec{A})$. to $\mathfrak{R}_{C}(O, X, Y, Z)$ such as: 


$$
[T]_{\mathfrak{R}_{C}}^{\Re_{S}}=\left[\begin{array}{ccc}
-\sin \eta \sin \beta & -\cos \beta & -\cos \eta \sin \beta \\
-\sin \eta \cos \beta & \sin \beta & -\cos \eta \cos \beta \\
\cos \eta & 0 & -\sin \eta
\end{array}\right]
$$

$N_{f}$ is the number of the tool teeth. $K_{R}, K_{T}$ and $K_{A}$ are respectively the specific coefficients: radial, tangential and axial, empirically defined. $\beta$ is the angle of width of cut $f_{z_{b}}$ is the feed per tooth.

First of all, this model is applied in the case of a plane surface, to end at a generalisation, carried out in the case of concave or convex inclined surfaces (Smaoui et al., 2008).

The study of this part milling will be afterwards elaborated, while taking into account the nature of the trajectory to be machined, and of the machining direction. It also takes into account the tool geometrical parameters, such as the axial and the radial depth of cut.

\subsection{Determination of the specific coefficients}

In order to determine the specific coefficients, in the three directions: tangential, radial and axial, respectively noted $K_{R}, K_{T}$ and $K_{A}$, the cutting forces $F_{X}, F_{Y}$ and $F_{Z}$ must be, first of all, measured. These parameters are bound by a model of cutting forces (Milfelner and Cus, 2003).

Figure 2 Different slopes to test (see online version for colours)
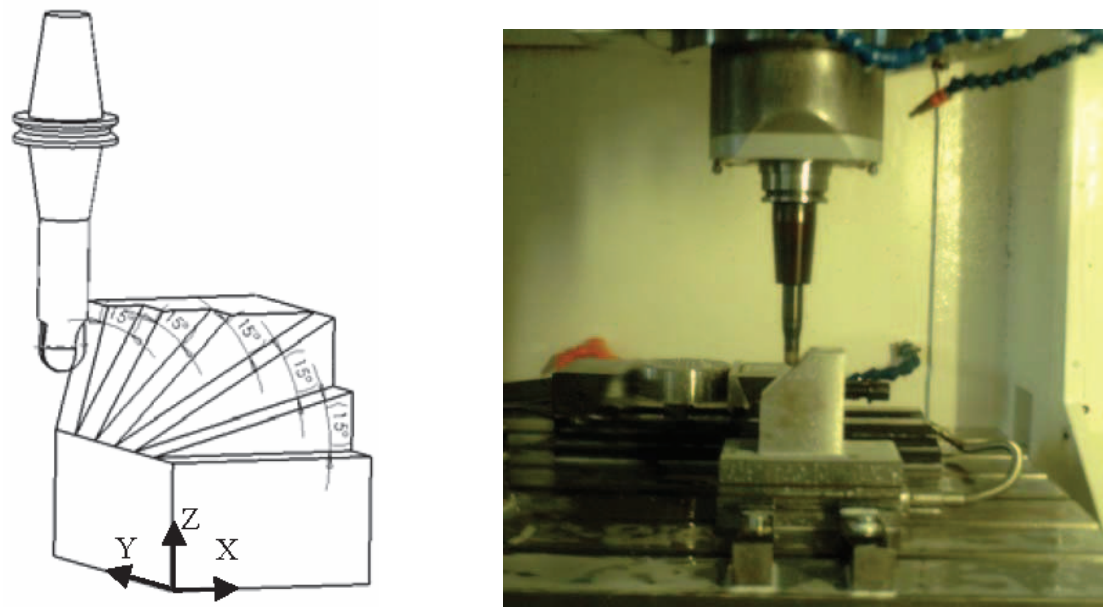

These coefficients necessarily vary according to the slope of the trajectory to be machined, and also according to the cutting conditions such as: feed per tooth $f_{z b}$, the cutting speed $V_{c}$ and the depth of cut: axial $A_{d}$ and radial $A_{r}$. Indeed, the changing of one of these parameters implies new coefficients.

For this reason, the specific coefficient behaviour is going to be defined according to the inclination angle of the surface to be machined, counted from the horizontal. A series of tests will be carried out, beginning with the machining of a surface of $75^{\circ}$ of inclination, and diminishing each time of an angle of $15^{\circ}$, until the horizontal state, as indicated in Figure 2. 
The adopted trajectory is a zigzag one: the tool carries out several go-and-backs, following $X$ and $-X$, which respectively correspond to an upward cut and a downward cut.

However, the specific coefficients $K_{R}, K_{T}$ and $K_{A}$ cannot be determined without having recourse to matrix of a reverse passage $[T]^{-1}$, which allows the passage from the elementary cutting forces $d F_{X}, d F_{Y}$ and $d F_{Z}$ in the Cartesian coordinate system $\mathfrak{R}_{C}(O, X, Y, Z)$ towards the elementary cutting forces in the local coordinate system $\Re_{S}(C, \vec{R}, \vec{T}, \vec{A})$ such as:

$$
\begin{aligned}
& \left\{d F_{R, T, A}\right\}=[T]^{-1}\left\{d F_{X, Y, Z}\right\} \\
& {\left[\begin{array}{l}
d F_{R} \\
d F_{T} \\
d F_{A}
\end{array}\right]=\left[\begin{array}{ccc}
-\sin \eta \sin \beta & -\cos \beta & -\cos \eta \sin \beta \\
-\sin \eta \cos \beta & \sin \beta & -\cos \eta \cos \beta \\
\cos \eta & 0 & -\sin \eta
\end{array}\right]^{-1}\left[\begin{array}{l}
d F_{X} \\
d F_{Y} \\
d F_{Z}
\end{array}\right]}
\end{aligned}
$$

The specific coefficients $K_{T}, K_{R}$ and $K_{A}$ are determined from the following equation (Milfelner and Cus, 2003):

$$
\left[\begin{array}{l}
K_{R} \\
K_{T} \\
K_{A}
\end{array}\right]=\frac{\sum_{i=1}^{N_{z}} \sum_{j=1}^{N_{\theta}} \sum_{k=1}^{N_{f}}[T]^{-1}(i, j, k)\left[\begin{array}{l}
\overline{F_{X}} \\
\frac{F_{Y}}{F_{Z}}
\end{array}\right]}{\sum_{i=1}^{N_{z}} \sum_{j=1}^{N_{\theta}} \sum_{k=1}^{N_{f}} f_{z_{b}} \sin [\beta(i, j, k)] d z}
$$

A ball-end cutting tool, $16 \mathrm{~mm}$ in diameter, having two-teeth $\left(N_{f}=2\right)$ and an angle of helix $i_{0}=9^{\circ}$, has been used. The part to be machined is made of steel, type XC38 (C35). The cutting conditions are defined by an axial depth of cut $A_{d}=1 \mathrm{~mm}$, a radial width of cut $A_{r}=3.873 \mathrm{~mm}$, a feed by tooth $f_{z b}=0.1 \mathrm{~mm} /$ tooth, and a spindle speed equal to 4,000 $\mathrm{rpm}$, on a high speed milling machine (HSM).

The cutting forces for the extreme angles of inclination, measured by a dynamometer platform (Kistler 9275B). Signals are analysed, due to the software Dynoware ${ }^{\odot}$. Figure 3 shows cutting forces for $\alpha=0^{\circ}$ and $\alpha=75^{\circ}$.

A magnified length, sampled from the cutting forces strips for this dynamometer surface, corresponding to $\alpha=0$, and compared to the simulations obtained by MATLAB ${ }^{\odot}$ software, is presented in Figure 4.

Figure 4 depicts that there is a correlation between the results obtained in simulation, and those obtained by the dynamometric plate.

The purpose of these series of tests, achieved for the different surfaces, and according to different inclinations, is to determine the specific coefficients variation, according to these slopes. This variation is presented in Figure 5. 
Figure 3 Variation of the cutting forces for the different angles of inclination in $\mathfrak{R}_{C}(O, X, Y, Z)$ (see online version for colours)
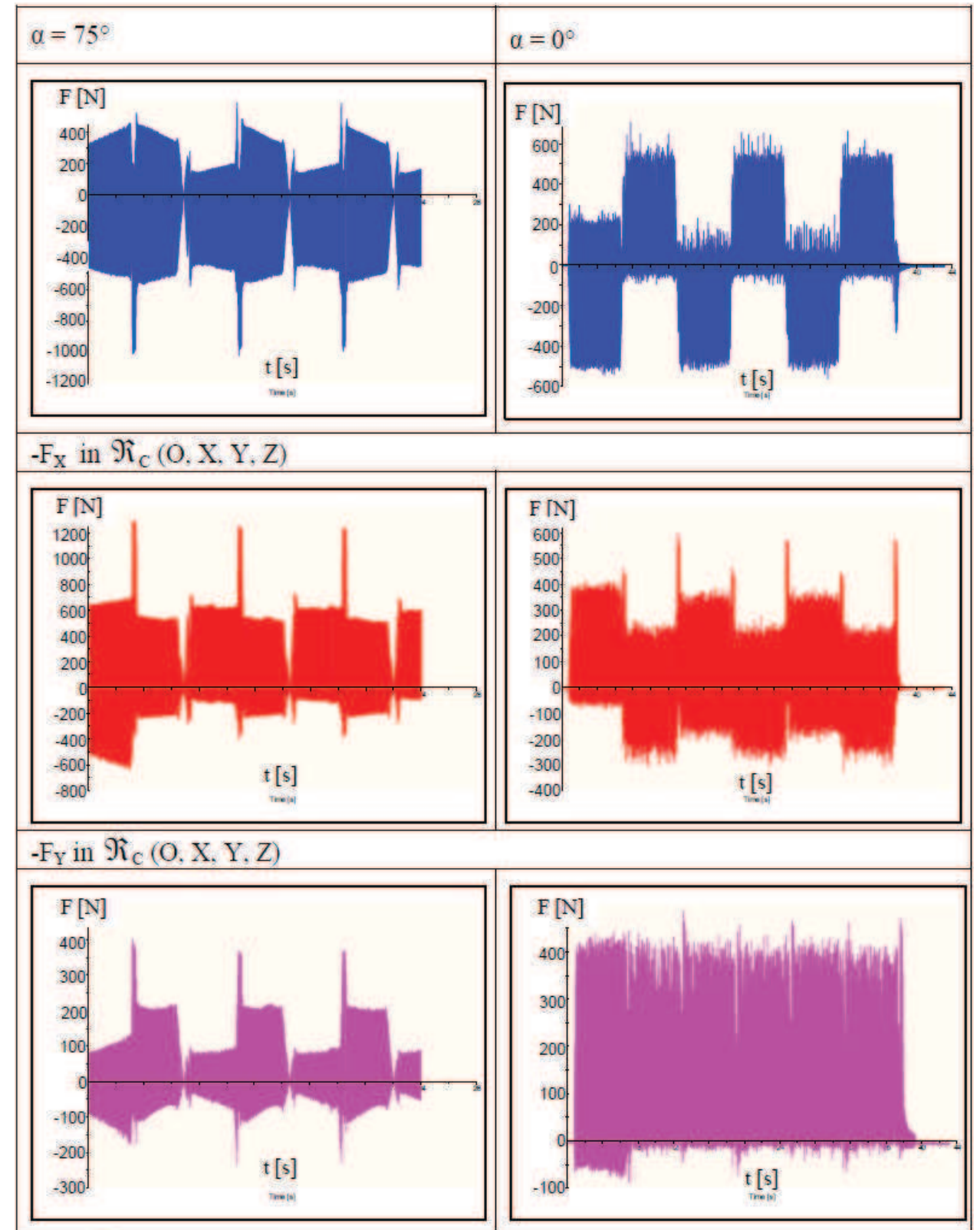

$\mathrm{F}_{\mathrm{Z}}$ in $\Re_{\mathrm{C}}(\mathrm{O}, \mathrm{X}, \mathrm{Y}, \mathrm{Z})$ 
Figure 4 Simulated and measured cutting forces (see online version for colours)

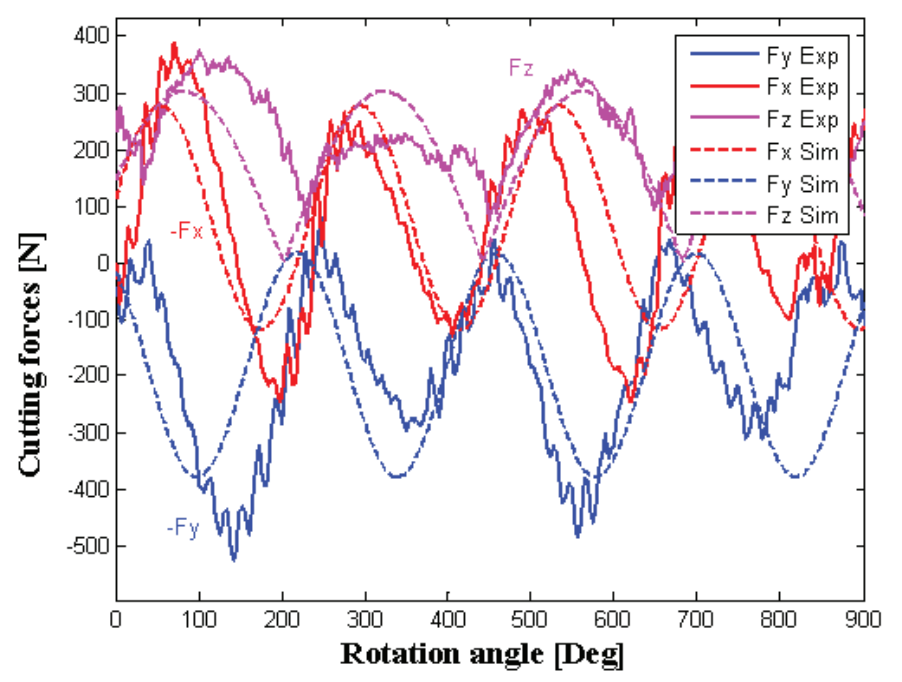

Figure 5 Variation of the specific coefficients according to the angle of inclination (see online version for colours)

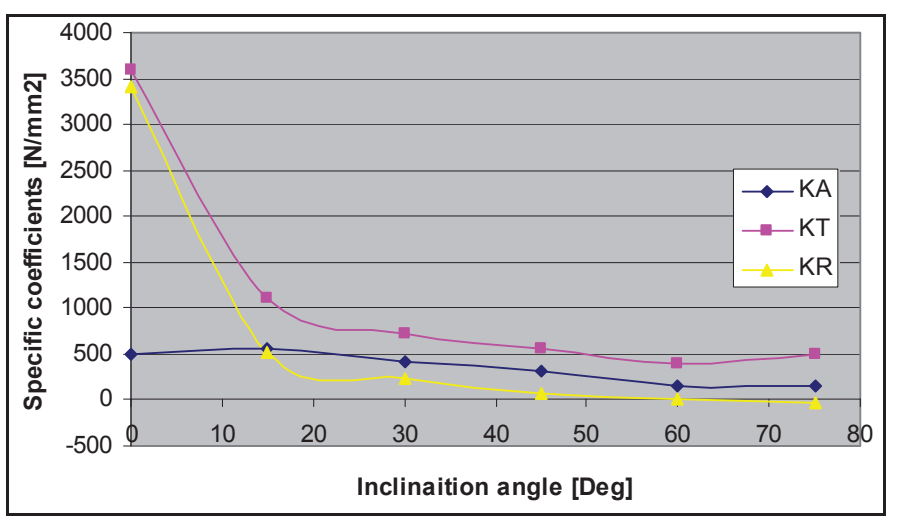

The variation of the specific coefficients must be introduced in the simulation program. For this reason, a curve of tendency is necessary, in order to find out the theoretical expression of the coefficients $K_{R}, K_{T}$ and $K_{A}$ according to the angle of inclination $\alpha$.

$$
\begin{aligned}
& K_{A}=7 E-06 \alpha 5-0.0013 \alpha 4+0.0899 \alpha 3-2.7111 \alpha 2+27.9 \alpha+500 \\
& K_{T}=-1 E-05 \alpha 5+0.0036 \alpha 4-0.3341 \alpha 3+14.867 \alpha 2-325.78 \alpha+3600 \\
& K_{R}=-3 E-05 \alpha 5+0.0062 \alpha 4-0.5215 \alpha 3+20.971 \alpha 2-409.27 \alpha+3400
\end{aligned}
$$

\subsection{Calculation of the cutting tool deflection}

In order to end at the compensation step, it is necessary to know how to determine the tool deflected trajectory, which is the deviated CAM trajectory. For this, it is necessary to 
simulate the tool deflected trajectory, according to the average force between two-successive nodes.

First, the cutting forces model has been applied on a plane surface. Second, it was compared to an experimental result, which has resulted in a perfect correlation. After, this same model has been generalised, in the case of an inclined surface, and another circular surface, but, by adopting each time a change of reference, depending on the angle of inclination (Smaoui et al., 2008).

The principle of this method consists, first of all, in determining the angle of inclination $\alpha$, for each segment joining these two-nodes (Figure 6), and in calculating the average force between two-successive nodes

Figure 6 Average cutting force determined all along the trajectory (see online version for colours)

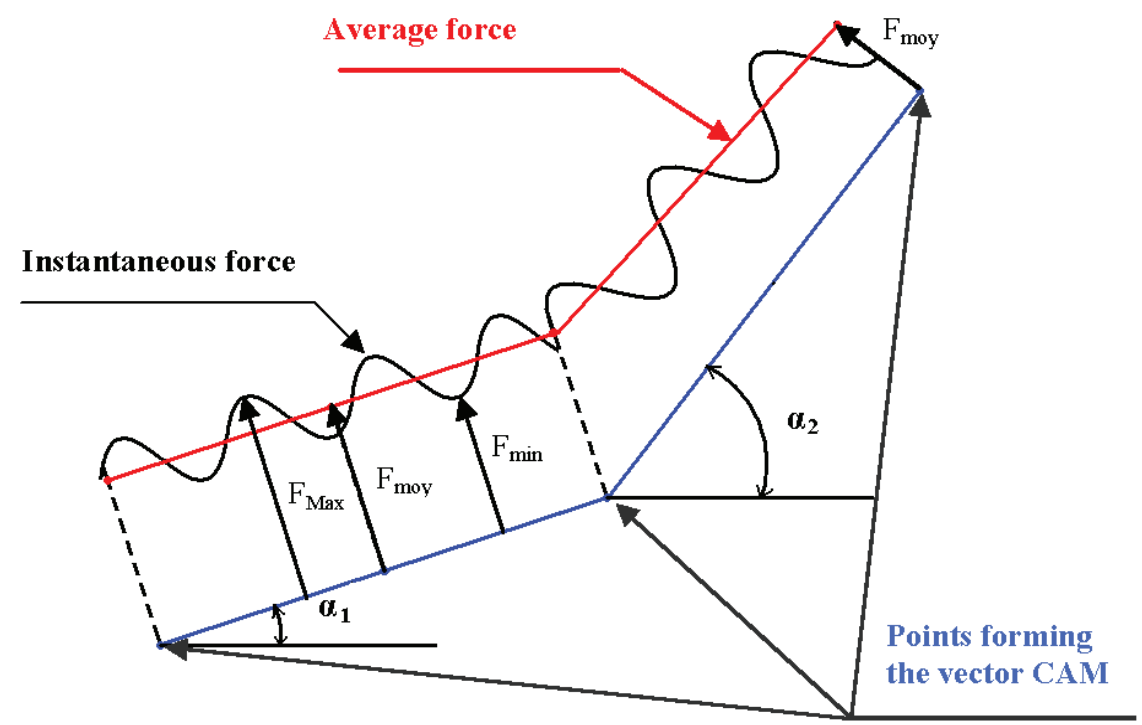

Once the cutting forces all along the tool trajectory are determined, the pertinent choice goes towards the finite elements method, in order to determine the tool deformation. It's a matter of applying a well determined force on the extremity of the tool in the $X$ direction. So, it is necessary to find out its deflection in the three directions $X, Y$ and $Z$. Then, the force directions is changed in the $Y$ way then in the $Z$ way, and deduce, once more, the tridimensional deflection value according to the force intensity.

The tool behaviour is presented further to the force exerted, following the $X$ direction $(\mathrm{F}=1,000 \mathrm{~N})$ (Figure7).

The total deflection is the sum of all the deflexions, due to the forces $F_{X}, F_{Y}$ and $F_{Z}$, applied simultaneously, following $X, Y$ and $Z$ axis, deduced by the finite elements method. It is presented as follows:

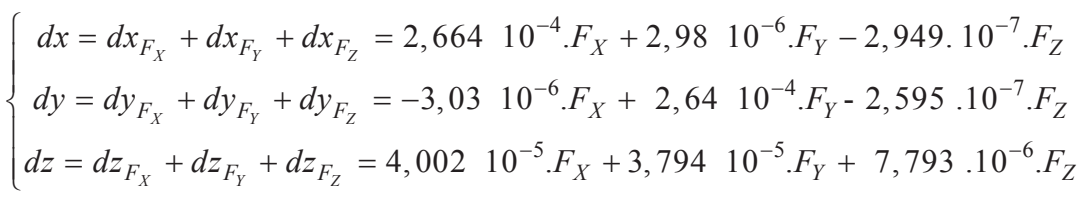


whole of nodes, constituting the CAM trajectory, are deviated according to the average cutting forces, calculated instantaneously, all along the cutting tool trajectory, swept during the machining. The CAM trajectory is instantaneously replaced by the points, which form the deflected (adopted) trajectory coordinates. It is this same trajectory which is going to be corrected by the mirror method before machining.

Figure 7 Deflection $\left(d x_{F_{X}}\right)$ following the $X$ axis for $\mathrm{F}=1,000 \mathrm{~N}$ (see online version for colours)

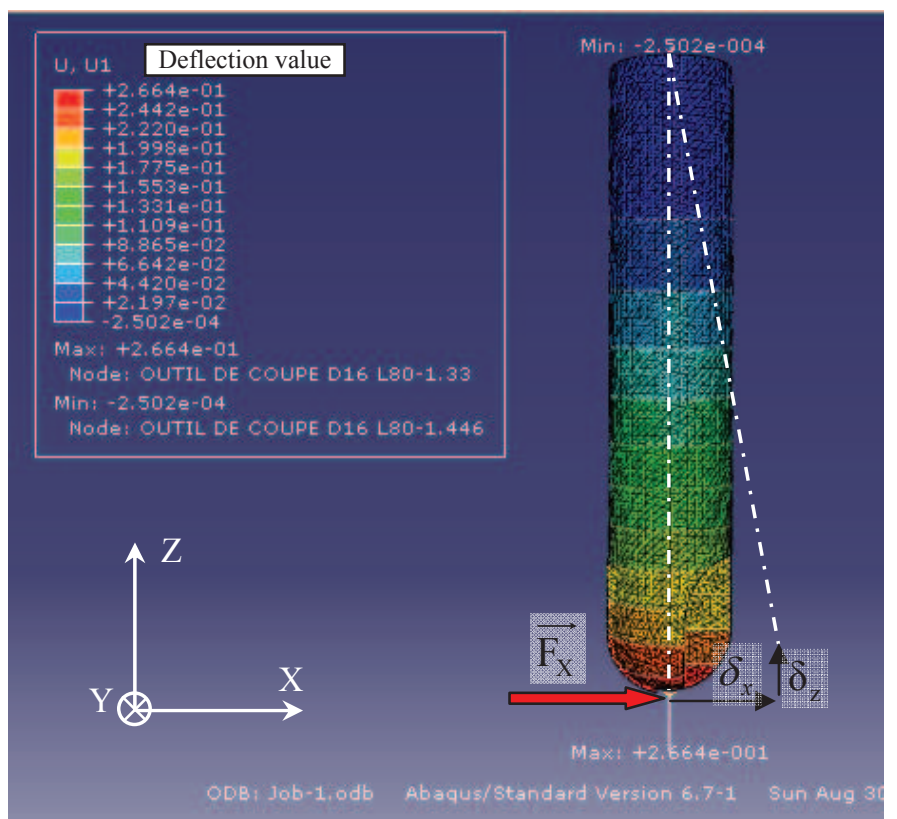

\section{Compensation method}

In order to compensate this deflection, a new process reveals to be necessary. The method proposed is based upon the tool trajectory modification. It is inspired from the mirror method (Hascoët et al., 1997). The latter is an iterative method, conceived for a contour machining, where the deflection is concentrated in the normal direction of the tool (Dépince and Hascoët, 2006). In this way, the mirror method is limited to a compensation, following only one direction, and so neglects the tangential direction. In this study, the deflection occurs on three directions $X, Y$ and $Z$. Hence, the need to a new method, able to remedy to this deflection.

The method proposed here, considers the two-trajectories: one is desired (CAM), having the coordinates $\left(x_{\text {desired }}, y_{\text {desired }}, z_{\text {desired }}\right)$, and the other is deflected. A first stage consists in compensating the trajectory of the values $d x, d y$ and $d z$, in the symmetrically opposite direction, according to the deflected trajectory. Figure 8 presents a simplified diagram of the compensated method for only one direction $d x$ among the three mentioned directions $d x, d y$ and $d z$. For this new position, a variation of the axial depth of cut $A_{d}$, of the radial width of cut $A_{r}$ and of the feed by tooth $f_{z b}$, respectively to the three directions 
$X, Y$ and $Z$, will appear. For this reason, the cutting forces and the new corresponding deflections, have to be, once more, calculated. These steps are going to be repeated $i$-times, in an iterative way, until the deflections will be inferior to a tolerance already fixed at the beginning of this procedure. For this example, the tolerance interval is fixed to $0.005 \mathrm{~mm}$. In this way, it becomes possible to reach the optimal trajectory, which will be imposed to the cutting tool ( $\left.x_{\text {imposed }}, y_{\text {imposed }}, z_{\text {imposed }}\right)$. This vector will be sent to the MasterCam $^{\odot}$ software, in order to achieve the part machining, according to the new coordinates.

Figure 8 Compensation method (see online version for colours)

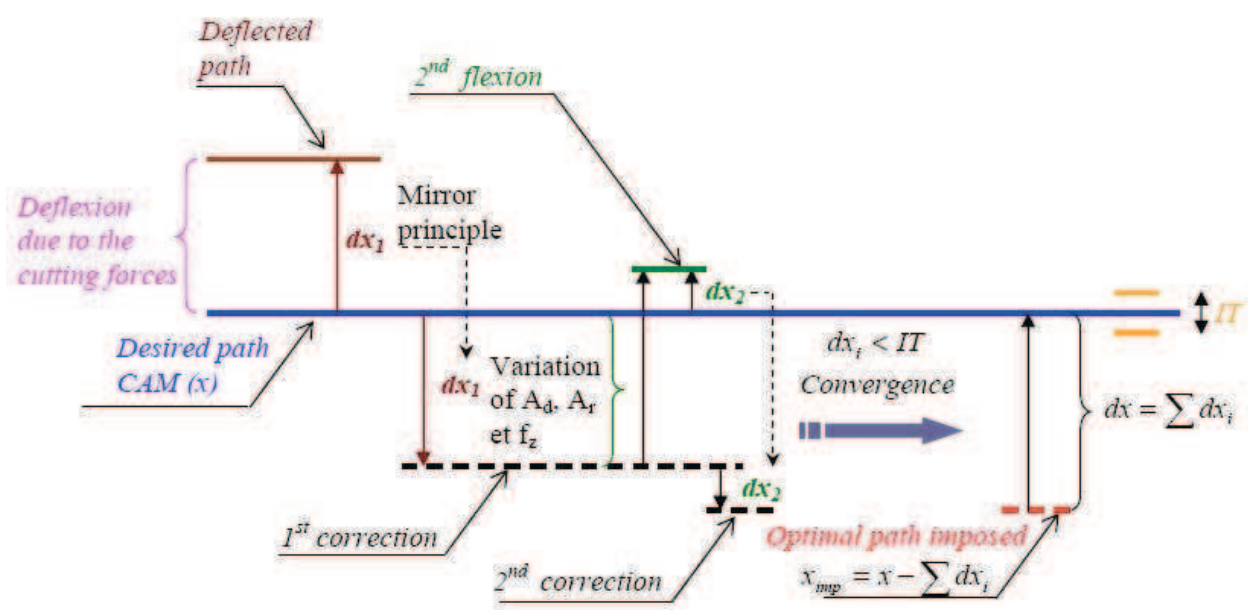

\section{Application of the compensation method}

We want to carry out the milling of a complex workpiece, having six-shapes of surfaces, with a length $L=220 \mathrm{~mm}$ and a width $l=78 \mathrm{~mm}$, as indicated in Figure 9 .

The same tool used here, is a ball-end tool of a ray equal to $8 \mathrm{~mm}$, having two-teeth $\left(N_{f}=2\right)$ and an angle of helix $i_{0}=9^{\circ}$. This tool fits in the workpiece with a feed of a value $f_{z b}=0.1 \mathrm{~mm} /$ tooth and an axial depth of cut $A_{d}=1 \mathrm{~mm}$.

Figure 9 Workpiece to be machined in 3D (see online version for colours)

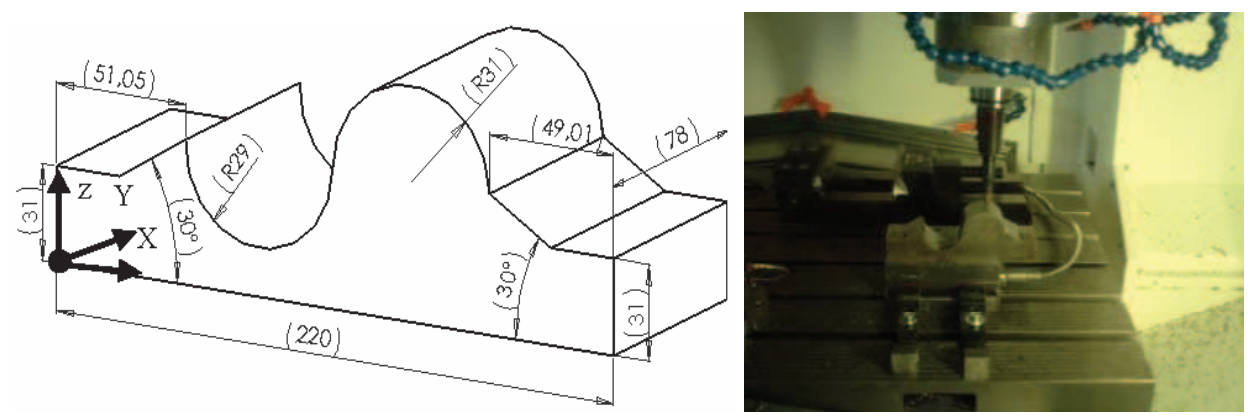


The two-finish tests: with and without compensation, are going to be realised on the same part. That is why, the two-test surfaces are going to be separated by a groove (12 mm width and $1 \mathrm{~mm}$ depth), so the two-machinings will be carried out under the same conditions (Figure 10).

Figure 10 Separation of the two-surfaces (see online version for colours)

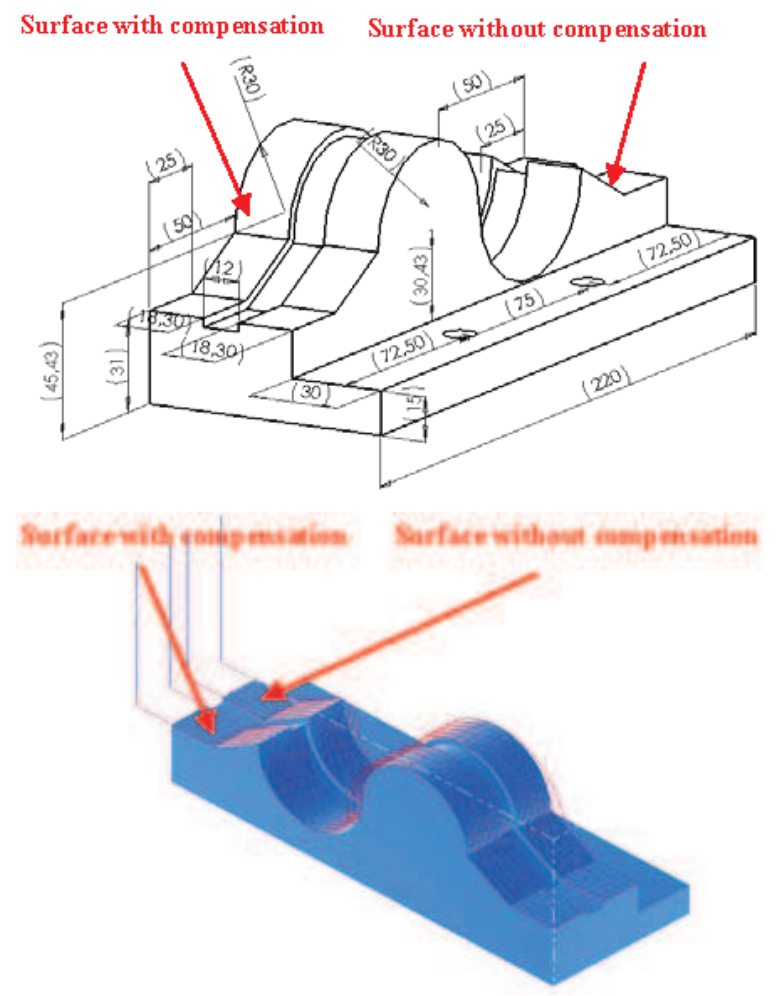

The cutting forces are calculated according to the nature of the trajectory part to be machined (flat, inclined...), and following the machining direction (following $X$ or $-X$ ).

Figure 11 shows the cutting forces evolution, following the tool-end trajectory. This trajectory is obtained from the coordinates of the points transferred from the software MasterCam ${ }^{\odot}$. It is of a zigzag type: the tool carries out several go-and-backs, following $X$ and $-X$. This respectively corresponds to an upward cut and a downward cut. The cutting forces are drawn in black for the $X$ machining, and in red for the $-X$ machining.

After simulating the cutting forces, the tool deflection is determined according to the average forces, all along the trajectory swept on the surface. The coordinates of the nodes forming the deflected (adopted) trajectory, are gathered in a vector. It is on this trajectory that the correction of the tridimensional trajectory is going to executed with the mirror method. This leads to find the compensated trajectory, which is going to be sent towards the machine (Figure 12), by means of a numerical control file (NC) generated by MasterCam $^{\circ}$. 
Figure 11 Cutting forces simulation in longitudinal milling, (a) $F X$ (b) $F Y$ (c) $F_{z}$ (see online version for colours)

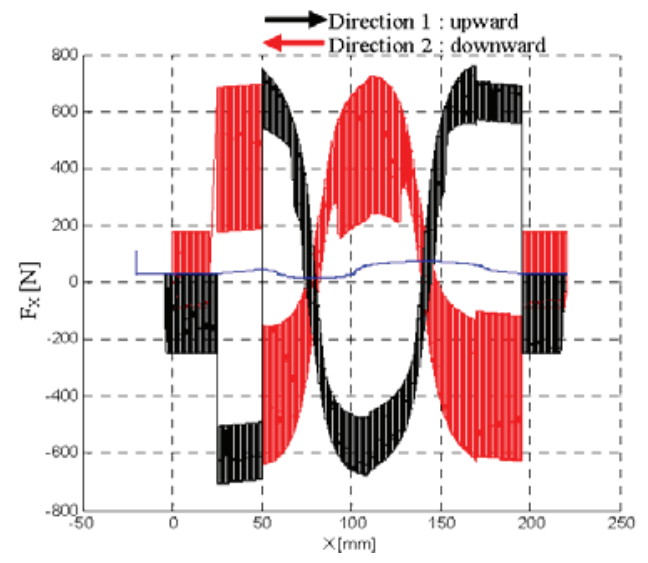

(a)

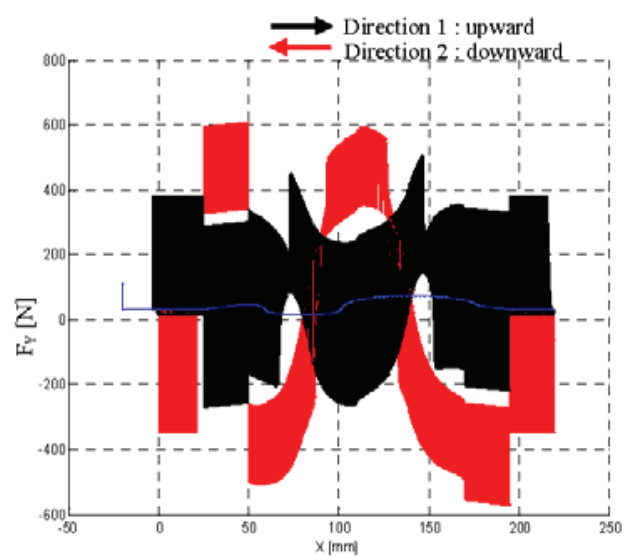

(b)

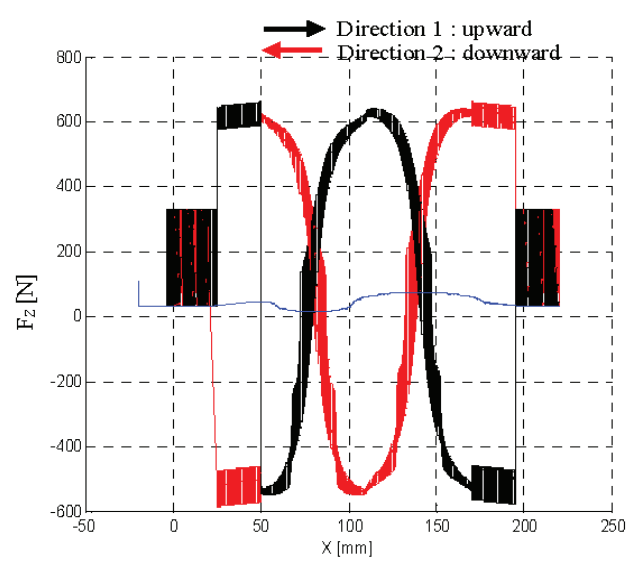

(c) 
Figure 12 The tool trajectory compensated in both directions (see online version for colours)

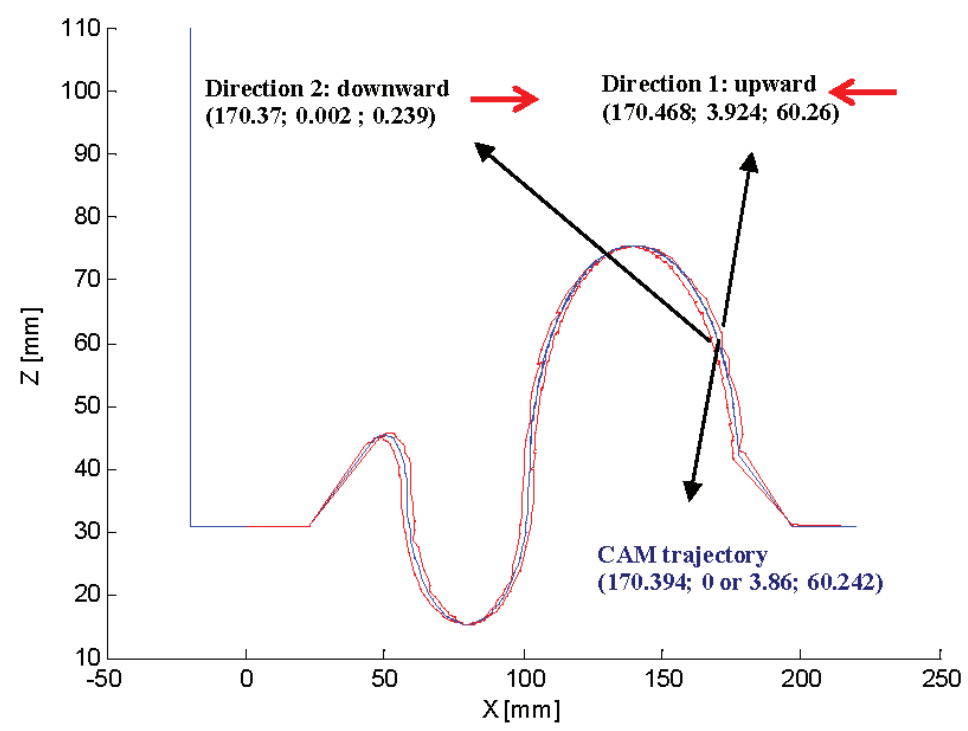

The coordinates of the points forming this path, will be sent to MasterCam ${ }^{\odot}$. So, the new compensated tool trajectory could be simulated. The two-NC files, containing the compensated and non-compensated trajectories, are sent to the machine, in order to tackle the machining in compensation.

\section{Results}

The two-compensated and non-compensated surfaces are measured on a $3 \mathrm{D}$ measuring machine (DEA GAMMA RECORD).

In order to confirm the validity and the precision of the compensation program, the compensated trajectory is going to palpate in order to determine the coordinates of the points constituting this trajectory (Figure 13).

Figure 13 Measurement of the geometry obtained by the two-tests (see online version for colours)

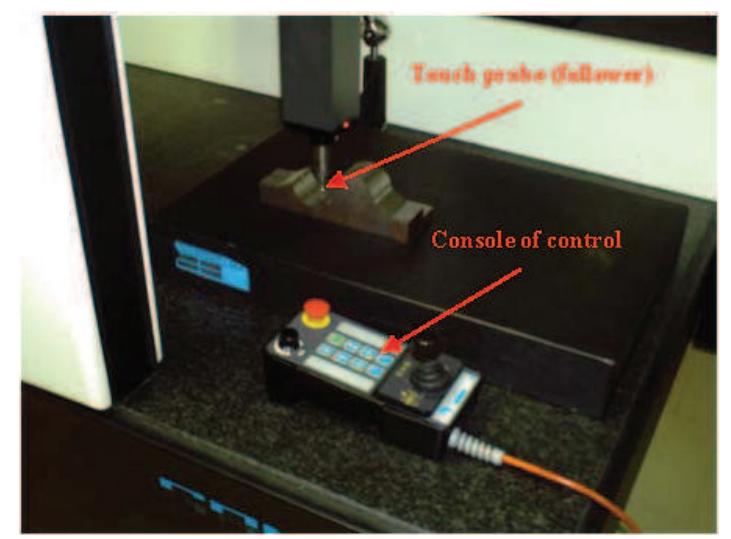


The coordinates noted down on the part, in the two-machined zones, (with and without compensation), made is possible to deduce a variable and important gain in the different tested zones represented in Figure 14.

Figure 14 Geometrical characteristics of the different tested zones

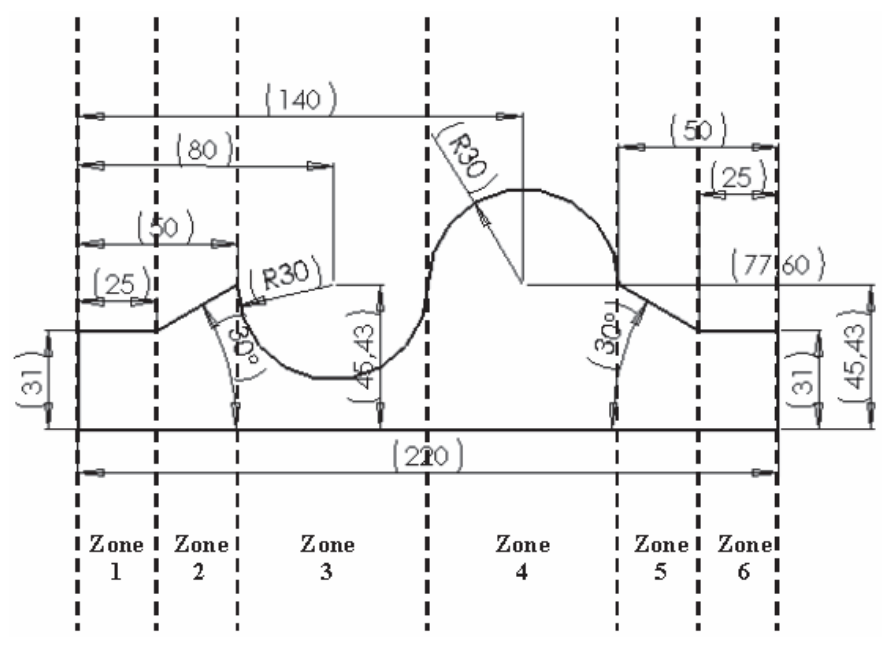

For the same coordinate in $X$, The difference in amplitude $(Z)$ for a sampling of the two-compensated and non-compensated surfaces constitutes the amplitude of the correction thus obtained. The latter is listed in Table 1. This geometrical difference, between the two-compensated and non-compensated surfaces, should normally be the nearest possible to the deflection simulated theoretically, in the same area. This area is theoretically located between two very successive nodes.

A second validity measurement has been achieved on the convex zone (zone 4), supposed to be $16 \mathrm{~mm}$ in diameter. Four-samplings of coordinates have been carried out following $X$ : $(141.8543 ; 155.1659 ; 161.9415 ; 170.4063)$, which corresponds respectively to a theoretical deflection equal to $(-0.0002 ; 0.1126 ; 0.1107 ; 0.0011)$ in the $X$ direction and $(0.0078 ; 0.0142 ; 0.0142 ; 0.0001)$ in the $Z$ direction.

An average deflection of the order of 0.056 has consequently been remarked.

Table 1 Geometrical correction obtained for the case of a downward cut

\begin{tabular}{lcc}
\hline Zone & Value of the correction & Estimated theoretical deflection \\
\hline 1 & -0.002 & -0.002 \\
2 & 0.014 & 0.014 et 0.015 \\
3 & 0.011 & 0.007 et 0.014 \\
4 & 0.009 & Between 0.006 and 0.01 \\
5 & -0.019 & Between -0.017 and 0.017 \\
6 & 0.003 & 0.03 \\
\hline
\end{tabular}

The touch probe has noted down an average diameter of $60.345 \mathrm{~mm}$ in the non-compensated area. However, for the compensated zone, the touch probe has recorded 
a diameter of $60.236 \mathrm{~mm}$, as indicated in the two following diagrams, given by Metrolog $^{(\mathcal{C}}$ software.

\begin{tabular}{ll}
\hline Inspection & Inspection \\
\# 193 CIRCLE Ref. Sys 1 & $\#$ 194 CIRCLE Ref. Sys 1 \\
X 336.7665 & X 336.7433 \\
Z 30.3189 & Z 30.3311 \\
DM 60.3454 & DM 60.2365 \\
ROUNDNSS 0.0574 & ROUNDNSS 0.0224 \\
\hline
\end{tabular}

It is to be noted that, on one hand, the deflection in the $X$ direction exerts a certain influence on the obtained curvature, since it is more important. On the other hand, and thanks to the recorded values, the radius value of the compensated zone is estimated to 30.173. Nevertheless, the radius value of the other non-compensated zone is of the order of 30.118 .

Figure 15 Tool deflection recorded in the direction of $X$ (see online version for colours)

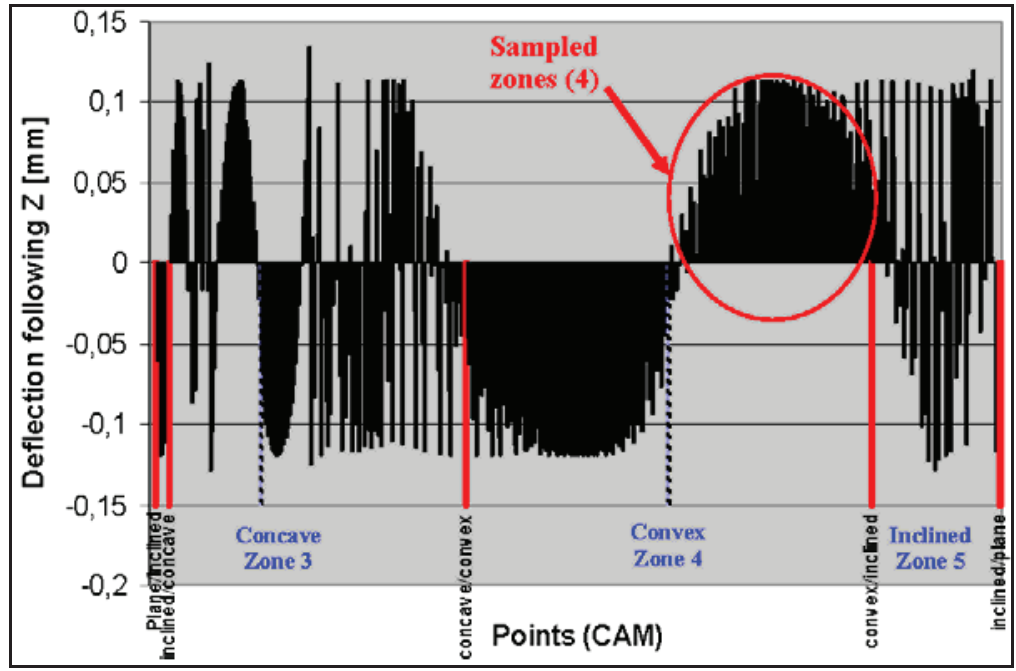

So, it becomes possible to deduce from this, that the difference between these two-radii is equal to 0.054 . This corresponds to the average value of the deflection occurring in this zone (Figure 15).

These results suitably concord with the values expected in simulation.

These results unequivocally confirm the results provided in this work and the precision of the methods chosen.

\section{Conclusions}

In this paper, a compensation method of the trajectory error is presented in order to be machined, which is based on the cutting tool deflection. The elementary cutting force has been calculated, for each discretised section, by means of the specific cutting force 
coefficients, in the local spherical reference $\mathfrak{R}_{S}(C, \vec{R}, \vec{T}, \vec{A})$. These coefficients have been extracted from the experimental results. Their theoretical expressions, according to the trajectory inclination, are injected in the compensation program. The tool, used here, is $16 \mathrm{~mm}$ in diameter, and the piece to be machined is made of steel type XC38 (C35).

The tool deflection, caused by these forces, has been studied once their simulation has been realised. This study is a preliminary step which makes it possible to carry out a correction of the trajectory, according to the machining tolerance.

Thus, the results obtained by the finite elements method are going to be used, in order to calculate the tool deflection in the three-directions according to the applied forces $F_{X}$, $F_{Y}$ and $F_{Z}$.

After that, a compensation method has been proposed for a change of the tool trajectory. The new coordinates of the points, which constitute the new trajectory, are exported towards the CAM software. This method has been applied in the case of a complex part machining. The simulation results have shown the advantage of the approach proposed since it has allowed to correct the machining errors and ended at an optimal trajectory respecting the machining tolerances.

Finally, two-parallel machinings, separated by a groove, have been achieved, on the same complex part and carried out absolutely in the same conditions, and with the same tool. The first machining corresponds to trajectory with compensation and the second to trajectory without compensation.

The coordinates of the two obtained surfaces are read by a 3D measuring machine. The comparison, between these two-surfaces, confirms the similarity in the results obtained by the two-methods, one with compensation and the other conceived in CAM.

\section{References}

Budak, E. and Altintas, Y. (1994) 'Peripheral milling conditions for improved dimensional accuracy', International Journal of Machine Tools and Manufacture, Vol. 34, pp.907-918.

Cho, M.W., Kim, G.H., Seo, T.I., Hong, Y.C. and Cheng, H.H. (2006) 'Integrated machining error compensation method using OMM data and modified PNN algorithm', International Journal of Machine Tools \& Manufacture, Vol. 46, pp.1417-1427.

Cho, M.W., Seo, T.I. and Kwon, H.D. (2003) 'Integrated error compensation method using OMM system for profile milling operation', Journal of Materials Processing Technology, Vol. 136, pp.88-99.

Dépince, P. and Hascoët, J.Y. (2006) 'Active integration of tool deflection effects in end milling. Part 2. Compensation of tool deflection', International Journal of Machine Tools \& Manufacture, Vol. 46, pp.945-956.

Fines, J.M. and Agah, A. (2008) 'Machine tool positioning error compensation using artificial neural networks', Engineering Applications of Artificial Intelligence, Vol. 21, pp.1013-1026.

Hascoët, J.Y., Seo, T.I. and Dépincé, P. (1997) 'Compensation des déformations d'outils pour la génération de trajectoires d'usinage', Proceedings of the 16th Canadian Congress of Applied Mechanics-CANCAM97, pp.569-570, Québec.

Huang, Y. and Hoshi, T. (2000) 'Optimization of fixture design with consideration of thermal deformation in face milling', Journal of Manufacturing Systems, Vol. 19.

Law, K.M.Y. and Geddam, A. (2001) 'Prediction of contour accuracy in the end milling of pockets', Journal of Material Processing Techniques, Vol. 113, pp.399-405.

Law, K.M.Y. and Geddam, A. (2003) 'Error compensation in the end milling of pockets: a methodology', Journal of Materials Processing Technology, Vol. 139, pp.21-27. 
Liu, Y.T., Chang, W.C. and Yamagata, Y. (2010) 'A study on optimal compensation cutting for an aspheric surface using the Taguchi method', CIRP Journal of Manufacturing Science and Technology, Vol. 3, pp.40-48.

Matsumura, T. and Ono, T. (2008) 'Cutting process of glass with inclined ball end mill', Journal of Materials Processing Technology, Vol. 200, pp.356-363.

Milfelner, M. and Cus, F. (2003) 'Simulation of cutting forces in ball-end milling', Robotics and Computer Integrated Manufacturing, Vol. 19, pp.99-106.

Seo, T.I. (1998) 'Integration of tool deflection during the generation of tool path', $\mathrm{PhD}$ thesis, in French, Université de Nantes-Ecole Centrale de Nantes.

Smaoui, M., Bouaziz, Z. and Zghal, A. (2008) 'Simulation of cutting forces for complex surfaces in ball-end milling', International Journal of Simulation Modelling, Vol. 7, pp.57-108.

Suh, S.H., Cho, J.H. and Hascoët, J.Y. (1996) 'Incorporation of tool deflection in tool path computation: simulation and analysis', Journal of Manufacturing Systems, Vol. 15, pp.190-199.

Wan, X.J., Xiong, C.H., Zhao, C. and Wang, X.F (2008) 'A unified framework of error evaluation and adjustment in machining', International Journal of Machine Tools \& Manufacture, Vol. 48, pp.1198-1210 